\title{
Educação superior pública e o Future-se: o projeto do capital em tempos de ascensão da extrema direita
}

\author{
Public higher education and the Future-se Program: the project \\ of capital in the rise of the far right
}

\author{
Antonio Gonçalves Filho* \\ Eblin Farage**
}

\begin{abstract}
Resumo - Este artigo traz algumas reflexões sobre a educação superior no Brasil a partir das determinações dos organismos internacionais, "sujeitos políticos coletivos" do capital. Aponta os processos advindos da crise internacional do capital e da crise do chamado socialismo real, que se expressam em profunda reestruturação do papel dos Estados nacionais, derivando em contrarreformas, nas diversas áreas sociais, como forma de minimizar o papel do Estado e garantir a apropriação privada do fundo público. Demonstra como a educação passa a ser considerada uma mercadoria importante na tentativa de reestruturação do capitalismo e aponta os principais eixos estruturantes do projeto de contrarreforma da educação superior do governo de extrema direita no Brasil, o Future-se.
\end{abstract}

Palavras-chave: educação superior; projeto do capital; contrarreforma da educação; Future-se.

\begin{abstract}
This article brings some reflections on higher education in Brazil from the determinations of international organizations, the "collective political subjects" of capital. It indicates the processes arising from the international crisis of capital and the crisis of the so-called real socialism, which are expressed in a profound restructuring of the role of national states, resulting in counter-reformations in the various social areas as a way of minimizing the role of the state and ensuring private ownership of public funds. It demonstrates how education is now considered an important commodity in the attempt to restructure capitalism and points out the main structuring axes of the Brazilian far-right government's higher education counter-reformation project, the Future-se Program.
\end{abstract}

Keywords: higher education; capital project; education counter-reformation; Future-se Program.

\footnotetext{
* É médico, professor da Faculdade de Medicina da UFMA, mestre em cirurgia experimental pela UFPR, doutor em fisioterapia clínica e experimental pela Uerj. Atualmente, presidente do Andes-SN. E-mail: antoniouro@ uol.com.br. ORCID: http://orcid.org/0000-0002-0232-9331.

** É assistente social, mestre em Serviço Social pela UFRJ e doutora em Serviço Social pela Uerj. Professora da Escola de Serviço Social da UFF e atualmente secretária geral do Andes-SN. E-mail: farage.eblin@gmail.com. ORCID: https://orcid.org/0000-0002-6307-8062.
} 


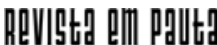

\} EDUCAÇÃO SUPERIOR PÚBLICA E O FUTURE-SE - GONÇALVES FH, A.; FARAGE, E. \}

DOI: $10.12957 /$ REP.2019.45210

\section{Introdução}

O ensino superior no Brasil deve ser por nós compreendido como resultado de um processo de amplas e longas disputas entre projetos distintos de sociedade e de formação. É nesse sentido que compreendemos que a educação é um projeto em disputa, em todos os níveis, da educação básica ao ensino superior. Uma disputa que tem início na definição do próprio caráter da educação, se pública e/ou privada. Como afirma Mészáros (2005, p. 27), "é necessário romper com a lógica do capital se quisermos contemplar a criação de uma alternativa educacional significativamente diferente".

Para os que compreendem que a educação é um direito social, e de todo(a)s, a defesa é de que deve ser laica, gratuita, socialmente referenciada e pública. Para outros segmentos, a educação é um produto e, nesse sentido, deve ser tratada como uma mercadoria, servindo dos interesses do desenvolvimento capitalista, de modo que pode ser vendida e esvaziada de sentido social.

As disputas em torno dos projetos de educação têm, de um lado, um conjunto de entidades ${ }^{1}$ sindicais, movimentos sociais e organizações de profissionais da educação, bem como o movimento estudantil. Estes defendem um projeto que tenha por base contribuir para a elevação do pensamento crítico e a leitura da realidade, a partir da totalidade da vida social e da compreensão das relações capital $x$ trabalho, tendo como horizonte a emancipação humana. Como afirmava Marx (2009, p. 71-72).

Só quando o homem individual retoma em si o cidadão abstrato e, como homem individual - na sua vida empírica, no seu trabalho individual, nas suas relações individuais -, se tornou ser genérico; só quando o homem reconhecer e organizar as suas forças próprias como forças sociais e, portanto, não separar mais de si a força social na figura da força política - (é) só então (que) está consumada a emancipação humana.

De outro lado, no projeto defendido pelo capital, que trata a educação como uma mercadoria, temos os defensores da educação para a qualificação da força de trabalho para o mercado e/ou como mercadoria no processo de revitalização dos fundos privados, sempre carregado de componente ideológico na tentativa de apassivamento da classe trabalhadora. Para Mészáros (2005, p. 35),

É por isso que hoje o sentido da mudança educacional radical não pode ser senão o rasgar da camisa-de-força da lógica incorrigível do sistema: perseguir de modo planejado e consistente uma estratégia de rompimento

\footnotetext{
1 As entidades sindicais, assim como o movimento estudantil e os movimentos sociais, têm profundas divisões e discordância sobre táticas e estratégias na condução da luta. Discordam também sobre que projeto é estruturante para a emancipação humana. Os distintos projetos defendidos pelas organizações/entidades/movimentos levam a divisões, que têmm reverberado em importante fragmentação e rebatido na organização da classe trabalhadora.
} 


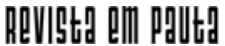

\} EDUCAÇÃO SUPERIOR PÚBLICA E O FUTURE-SE - GONÇALVES FH, A.; FARAGE, E. \}

DOI: $10.12957 /$ REP.2019.45210

do controle exercido pelo capital, com todos os meios disponíveis, bem como com todos os meios ainda a ser inventados, e que tenham o mesmo espírito.

Vale destacar que os efeitos do projeto do capital aparecem como desconexos, mas representam o conjunto das ações impostas para a educação superior com o objetivo de transformá-la em mercadoria. Nesse processo, as indicações do Banco Mundial (BM), da Organização das Nações Unidas para a Educação, Ciência e a Cultura (Unesco) e da Organização Mundial do Comércio (OMC), uma vez que são "sujeitos políticos coletivos do capital" (LIMA, 2007, p. 17), são absorvidas sobre a perspectiva da "modernização" e da necessidade de alinhamento internacional com a política da educação superior. Submetem, assim, um conjunto de países, em especial os de capitalismo tardio, como os da América Latina, a um mesmo processo educacional. Como afirma Lima (2007, p. 17):

A difusão destas noções cruciais da ideologia burguesa é realizada pelos organismos internacionais do capital no sentido de configurar as bases políticas do processo de mundialização financeira e mundialização de uma nova sociabilidade burguesa, no qual a educação escolar tem papel central.

Nesse sentido, deve-se efetuar a defesa de uma universidade pública, gratuita, laica, estatal, socialmente referenciada e antipatriarcal, que consiga garantir, como defende o Andes-SN (2013, p. 17), a "capacidade de assegurar uma produção de conhecimento inovador e crítico, que respeite a diversidade e o pluralismo, contribuindo para a transformação da sociedade". Essa se torna uma luta imprescindível.

\section{As crises e contrarreformas: traços do projeto do capital}

Compreender a situação da educação superior pública na atualidade nos coloca o desafio de analisar a realidade social para além do imediato. Buscar compreender a realidade presente apenas por ela mesma é o caminho mais fácil, mas também o mais superficial. Por isso, pensar o projeto de contrarreforma da educação superior do século XXI implica pensar as duas principais crises ocorridas no final do século $X X$, quais sejam, a crise estrutural do capitalismo e a chamada crise do socialismo real.

A crise estrutural do capitalismo supera, em termos de qualidade e importância, as crises cíclicas, e é marcada, a partir da década de 1970, pela impossibilidade de recuperar as taxas de lucro do capital. Assim, o capitalismo busca novas formas para garantir sua ampliação e reprodução, podendo ser resumido em seis elementos estruturantes, quais sejam: a) o aprofundamento da desigualdade e a ampliação do fosso entre ricos e pobres 


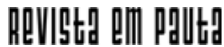

\} EDUCAÇÃO SUPERIOR PÚBLICA E O FUTURE-SE - GONÇALVES FH, A.; FARAGE, E. \}

DOI: $10.12957 /$ REP.2019.45210

no interior de cada país e entre os países; b) a necessidade de reconfiguração do papel do Estado, com restrição de sua ação social e apropriação do fundo público; c) a ampliação do uso da força para a manutenção do controle social sobre o(a)s trabalhadore(a)s; d) o aumento do pauperismo; e) uma nova morfologia do trabalho, que redesenha o mundo do trabalho; e f) o recrudescimento do conservadorismo, na busca de ampliação do domínio social.

Por outro lado, e não com menor importância, em âmbito mundial, vivemos também uma crise no campo da organização do(a)s trabalhadore(a)s, imposta pelo chamado "fim do socialismo real", com a Queda do Muro de Berlim em 1989 e o fim da União Soviética, em 1991. Os impactos dessa crise, entre muitos e complexos aspectos, podem ser condensados em alguns elementos: a) crise no interior das organizações de esquerda; b) fragmentação das organizações e entidades no campo do(a)s trabalhadore(a)s; c) busca pela reforma do sistema na perspectiva de "humanização" do capital, e não mais pela sua superação; e d) descrença, por uma parte da esquerda, na possibilidade de superação da ordem do capital, limitando a luta e as ações políticas a reformas e lutas institucionais dentro da ordem, desencadeando uma priorização da luta institucional (parlamentar e governamental) em detrimento da organização autônoma do(a)s trabalhadore(a)s.

A crise estrutural do capitalismo vai exigir, no Brasil e em parte do mundo, uma reconfiguração dos Estados Nacionais baseada em desoneração do Estado, mercantilização das políticas públicas e recrudescimento do conservadorismo. Essa receita tem como pano de fundo o projeto neoliberal, que se apresenta com impactos distintos nos diferentes países a partir das particularidades nacionais.

Os impactos dessa crise se fazem sentir de forma devastadora em países de capitalismo tardio, como o Brasil, já que somos um país que não fez sequer reformas, um dos últimos países do mundo a abolir a escravidão, com conquistas democráticas parciais. Como afirma Lima (2005, p. 4), seguimos um padrão que:

Estará expresso através de um 'imperialismo total' (Fernandes, 1975a) que (a) organiza a dominação externa a partir de dentro e em todos os níveis da ordem social, desde o controle da natalidade, da comunicação e o consumo de massa, até a importação maciça de tecnologia e de uma concepção de educação voltada para a formação da força de trabalho e para a conformação aos valores burgueses; (b) aprofunda as dificuldades para que os países latino-americanos garantam seu crescimento econômico em bases autônomas e, (c) estimula o fato de que nas economias periféricas, como ocorre com os interesses privados externos, os interesses privados internos estejam empenhados na exploração do subdesenvolvimento como estratégia para garantir sua lucratividade.

Nossa história de país colonizado, de "democracia" tutelada e gerida pelos interesses da burguesia, passa por mais de 20 anos de ditadura 


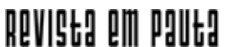

\} EDUCAÇÃO SUPERIOR PÚBLICA E O FUTURE-SE - GONÇALVES FH, A.; FARAGE, E. \}

DOI: $10.12957 /$ REP.2019.45210

empresarial-civil-militar, e só em 1988 (há menos de 30 anos) "conquista" uma Constituição Federal (CF/88), que avança em alguns direitos do(a)s trabalhadore(a)s (BRASIL, 1988).

Nesse sentido, tratar da educação superior nessa conjuntura nos impõe fazer uma breve análise do momento político que vivemos no Brasil, vinculado com o desenvolvimento capitalista internacional, em crise desde a década de 1970. Como já apontava Marx (2001), o capitalismo é um sistema político-econômico-social e cultural cuja existência está atrelada a crises cíclicas, que exigem sua reconfiguração na forma de gestão do Estado e/ou da produção. As crises, segundo o autor, são cada vez menos espaçadas, aprofundando a pauperização da classe trabalhadora e as expressões da questão social, nos termos de lamamoto e Carvalho (1995).

A crise cíclica e estrutural do capitalismo impõe uma reconfiguração do papel do Estado, de forma a atender às exigências imediatas para a recuperação do sistema capitalista, em especial a partir da tentativa de elevação de suas taxas de lucro. A cada crise, alternativas no campo político e econômico são gestadas, com rebatimentos importantes na vida social, cultural e política da classe trabalhadora.

Já foram construídas como alternativa à crise capitalista diferentes formas de gestão do Estado e da desigualdade social. Em alguns países da Europa, como experiência restrita, a partir da década de 1950 se gestou um modelo de Estado "protetor", o Estado de Bem-Estar Social. Esse modelo buscou superar a crise capitalista da década de 1930, repercutindo em várias partes do mundo, como um modelo almejado de Estado mais "humano", dentro da ordem do capital.

Na Europa, como no Brasil, inaugura-se, a partir dos anos de 1980, uma nova fase do capitalismo monopolista, o qual, não conseguindo se recuperar da crise iniciada na década de 1970, passa a exigir uma nova reconfiguração do Estado, apresentando-se em uma perspectiva neoliberal. O neoliberalismo, como afirma Anderson (1995, p.10), "foi uma reação teórica e política veemente contra o Estado intervencionista e de bem-estar".

No Brasil, a política neoliberal começa a ser desenvolvida na década de 1990, no governo de Fernando Collor de Mello (1990-1992), e mais especialmente a partir do governo de Fernando Henrique Cardoso $\left(\mathrm{FHC}\right.$ - 1995-2002) ${ }^{2}$ - que investiu na privatização clássica das empresas estatais, na recuperação da economia através do controle dos juros, na consolidação do Plano Real e na retirada de direitos do funcionalismo público, atacando as políticas públicas, entre outros.

A década de 1990 marca, portanto, a contradição entre o início do desenvolvimento da política neoliberal no Brasil e a luta pela efetivação da CF/88, que, apesar de traços liberais, traz em seu conteúdo importantes

${ }_{2}^{2}$ FHC havia sido ministro da Fazenda do governo de Itamar Franco (1992-1995), quando lançou o Plano Real, que se manteve como carro-chefe de seu primeiro governo. 


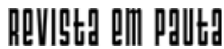

\} EDUCAÇÃO SUPERIOR PÚBLICA E O FUTURE-SE - GONÇALVES FH, A.; FARAGE, E. \}

DOI: $10.12957 /$ REP.2019.45210

conquistas para a classe trabalhadora. Esse novo patamar de direito conquistado na CF/88 foi frontalmente atacado a partir do projeto de reconfiguração do Estado iniciado pela política neoliberal, em especial a partir do Plano Diretor de Reforma do Aparelho do Estado, conduzido por Luiz Carlos Bresser Pereira, então ministro da Administração e Reforma do Estado, em 1995, no governo de FHC.

Conquistamos formalmente, na CF/88, direitos através de lutas e reivindicações dos movimentos organizados; porém, sua implementação e concretização passaram a ser ameaçadas pelo projeto neoliberal. O que nem havia sido consolidado começa a ser desmontado. Educação, saúde, previdência e assistência social passam a ser consideradas como mercadorias para contribuir na revitalização do capitalismo. O tripé da Seguridade Social passa a ser entendido como meio de apropriação do fundo público pela iniciativa privada, proliferando fundos de previdência complementar, planos de saúde conveniados a equipamentos públicos e organizações sociais para gerir as políticas de assistência social. Assim, a partir da segunda metade da década de 1990 tem início o desmonte do que ainda nem havia se consolidado, ficando inconcluso o processo de conquista e efetivação dos parcos direitos no Brasil.

A área da saúde atravessa um longo e penoso processo de privatização interna, com o repasse da gestão de importantes setores, como a atenção básica, para organizações sociais (OS) e/ou organizações não governamentais (ONGs). Além disso, aprofunda-se a parceria público-privada com o repasse de verba pública para instituições privadas, em especial no atendimento de alta complexidade, e por fim impulsionam-se os planos de saúde.

A Previdência Social, outro setor do tripé da Seguridade Social, tem sido submetida a várias contrarreformas desde o governo de FHC, com a instituição do fator previdência; depois, em 2003, no Governo Lula, com o fim da paridade entre servidores públicos ativos e aposentados, fim da aposentadoria integral e a taxação dos aposentados; e, em 2012, no Governo Dilma, com a criação do Fundo de Previdência Complementar dos Servidores Públicos Federais (Funpresp), que inaugura a aposentadoria complementar para o funcionalismo público federal, colocando os servidores que ingressaram após 2013 no teto, rebaixado, do regime geral de Previdência Social.

A quarta e mais intensa reforma da previdência, proposta pelo Governo Temer a partir de 2016, não se concretizou, dada a pressão organizada e combativa das entidades sindicais e movimentos sociais, e também pelo fato de estarmos próximos a eleições gerais no país. Em 2019, com a ascensão da extrema direita ao Governo Federal, a partir da eleição do Presidente Jair Bolsonaro, do Partido Social Liberal (PSL), uma "nova previdência" passa a ser discutida. Essa foi votada na Câmara Federal, com pouca resistência no primeiro turno, em julho, e, no segundo turno, em agosto do mesmo ano, sendo encaminhada para tramitar no Senado. 


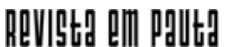

\} EDUCAÇÃO SUPERIOR PÚBLICA E O FUTURE-SE - GONÇALVES FH, A.; FARAGE, E. \}

DOI: $10.12957 /$ REP.2019.45210

Essa contrarreforma da previdência deve ser considerada uma das piores e mais perversas, já que acaba com a perspectiva da previdência pública, aumenta o tempo de contribuição e de trabalho, aumenta a idade mínima para aposentadoria e reduz as pensões por morte e por invalidez. Segundo os meios de comunicação anunciam, a capitalização, que foi retirada para a tramitação no Congresso, retornará como proposta de emenda parlamentar (PEC) paralela, para facilitar sua aprovação, o que significa mais uma ação voltada para o setor rentista da burguesia.

No que tange à legislação trabalhista, entre as muitas medidas que retiraram direitos dos trabalhadores e precarizaram as políticas públicas, merece destaque a aprovação da terceirização das atividades-meio ainda no Governo FHC, impondo a privatização gradual das políticas públicas, com a terceirização e consequente precarização de vários serviços e setores. Em 2017, no Governo Temer, com a aprovação da terceirização da atividadefim, do trabalho intermitente e da contrarreforma trabalhista, praticamente põe-se fim à Consolidação das Leis do Trabalho (CLT), de 1943, impondo um retrocesso de 50 anos aos trabalhadores no Brasil. E já no primeiro ano do governo de extrema direita de Jair Bolsonaro, no mês de agosto, teve início a votação da medida provisória (MP) 881, que trata da "liberdade econômica", contribuindo ainda mais para melhorar a vida dos empresários. Em sua análise na Câmara, a MP 881 incorporou outros artigos que alteram as leis trabalhistas, sendo considerada uma "minirreforma trabalhista" a favor dos empresários.

Todas essas ações, que guardam vínculos com as propostas do Plano Diretor do Governo FHC, e portanto com o projeto de contrarreforma do Estado do neoliberalismo, intensificam a submissão da economia brasileira aos interesses do desenvolvimento capitalista internacional e às exigências dos organismos internacionais, como Banco Mundial, Fundo Monetário Internacional (FMI) e Organização para Cooperação e Desenvolvimento Econômico (OCDE), deixando em último plano os interesses da classe trabaIhadora. Como afirma o documento do Ministério de Administração Federal e Reforma do Estado (Mare), "Estado e mercado, direta ou indiretamente, são as duas instituições centrais que operam na coordenação dos sistemas econômicos" (BRASIL, 1995, p. 9). Nesse sentido, Estado e mercado caminharam juntos no fortalecimento do capitalismo ao longo de toda a história brasileira desde a República.

Os ataques aos direitos do(a)s trabalhadore(a)s, que se apresentam como contrarreformas, atingem também a educação, como veremos a seguir, e devem ser analisados a partir do estágio atual do capitalismo. Nesta fase, que combina diferentes formas de expropriação da mais-valia, a partir da lógica do desenvolvimento desigual junto ao capitalismo, implementa-se uma reordenação das relações sociais.

A crise é tão profunda que, além de combinar a alta exploração da classe trabalhadora, em suas diferentes modalidades, faz necessário 


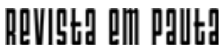

\} EDUCAÇÃO SUPERIOR PÚBLICA E O FUTURE-SE - GONÇALVES FH, A.; FARAGE, E. \}

DOI: $10.12957 /$ REP.2019.45210

utilizar formas arcaicas e até mesmo superadas de sociabilidade, a partir de uma regressão humanitária. Nesse sentido, consideramos que a atual crise do capitalismo não pode prescindir de: a) intensificar a exploração do(a)s trabalhadore(a)s a partir da articulação de diferentes formas de extração da mais-valia; b) avançar no uso da tecnologia como forma de ampliar os lucros; c) mercantilizar a vida e tudo que faz parte das relações sociais contemporâneas; d) apropriar-se, privadamente, do fundo público; e e) retroceder em padrões civilizatórios como possibilidade de ampliar a exploração e reavivar antigas formas de extração de mais-valia, baseadas na desumanização, a partir do conservadorismo.

Ou seja, vivemos hoje a crise internacional do capital aliada a uma fase obscurantista, que imaginávamos não ser mais cabível na civilização que havíamos conquistados. De fato, isso nos remete à afirmação de Marx (2007, p. 46), no Prefácio da Contribuição à economia política, em que ele diz que "com essa formação social [burguesa] termina, pois, a préhistória da sociedade humana".

\section{Contrarreforma da educação: um salto ao passado com o Future-se}

A história da educação superior pública no Brasil, em especial a partir do período da Ditatura empresarial-civil-militar (1964-1985), com os acordos MEC-Usaid ${ }^{3}$, foi direcionada pelos interesses dos organismos internacionais.

Florestan Fernandes (1975) considera que o padrão compósito de hegemonia burguesa instaurado no Brasil fez com que a conservadora burguesia brasileira tivesse dificuldades, ao longo da nossa história, em garantir até mesmo as reformas educacionais exigidas pelo próprio capitalismo. Para uma sociedade que não viveu a 'revolução burguesa clássica', a concepção burguesa de 'revolução educacional'4 significava um conjunto de avanços relativos. (ADUFF, 2013, p. 7-8).

O padrão de dominação da hegemonia burguesa é caracterizado pela associação entre os interesses das oligarquias agrárias e dos setores intermediários em formação, combinando diferentes formas de exploração da classe trabalhadora, e submisso à burguesia internacional.

Por isso tal padrão de hegemonia burguesa anima uma racionalidade extremamente conservadora, na qual prevalece o intento de proteger a

\footnotetext{
${ }^{3}$ Acordos firmados entre o governo brasileiro e o governo dos Estados Unidos.

${ }^{4}$ Ao tratar da concepção burguesa de "revolução educacional", Florestan (1975) faz referência às exigências do próprio capitalismo quanto à ampliação de acesso à educação como estratégia de qualificação da força de trabalho e de difusão da concepção de mundo burguesa, nos marcos do processo de urbanização-industrialização brasileiro.
} 


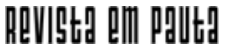

\} EDUCAÇÃO SUPERIOR PÚBLICA E O FUTURE-SE - GONÇALVES FH, A.; FARAGE, E. \}

DOI: $10.12957 /$ REP.2019.45210

ordem, a propriedade individual, a iniciativa privada, a livre empresa e a associação dependente, vistas como fins instrumentais para a perpetuação do superprivilegiamento econômico, sociocultural e político. (FERNANDES, 1975, p. 108).

Nesse ínterim, gradativamente a educação superior pública passa a ser hegemonizada pela iniciativa privada no Brasil. Como aponta Sguissardi (2008), no início da Ditadura Militar, 61,6\% do ensino superior era público e $38,4 \%$, privado; em dez anos o quadro se modifica drasticamente, passando as instituições privadas a controlarem $63,6 \%$ das matrículas, enquanto as instituições públicas ficavam com $36,4 \%$. Hoje, segundo os dados do censo da educação superior de 2016, divulgados pelo Instituto Nacional de Estudos e Pesquisas Educacionais Anísio Teixeira (INEP-MEC, 2017), 82,3\% das matrículas em 2016 foram em instituições privadas de ensino, demonstrando a grandiosa mercadoria em que a educação superior se transformou.

O Future-se, projeto de contrarreforma universitária do Governo Bolsonaro, foi apresentado, de forma restrita, no dia 16 de julho para reitores das universidades e institutos federais, e lançado oficialmente no dia 17 de julho, em solenidade na sede do Inep, em Brasília. O programa, que rapidamente foi transformado em projeto de lei, intitula-se "Programa Institutos e Universidades Empreendedoras e Inovadoras", e em sua forma e conteúdo representa um dos mais graves ataques à educação pública superior brasileira.

Tendo como "finalidade o fortalecimento da autonomia administrativa e financeira das Instituições Federais de Ensino Superior (Ifes), por meio de parceria com organizações sociais e do fomento à capitação de recursos próprios" (art. 19), já explicita a intenção do Governo Federal de se desresponsabilizar da educação superior pública (BRASIL, 2019). Ou seja, na perspectiva do Future-se, as organizações sociais e o mercado são mais capazes de prover o desenvolvimento do conhecimento do que o próprio Estado.

O projeto se estrutura em três eixos, que são: 1) gestão, governança e empreendedorismo; 2) pesquisa e inovação; e 3) internacionalização (BRASIL, 2019). Eixos distribuídos em 45 artigos e que necessitam da alteração de 17 leis. Todo o projeto é baseado na reestruturação do setor público de ensino superior a partir da vinculação com organizações sociais e fundos de investimento, consagrando a educação como uma mercadoria e negando sua função de direito social .

Há que se destacar que, ao contrário do que alguns pensam, o sistema público de educação superior no Brasil é um dos mais importantes e estruturados da América Latina, em grande parte pela luta de mais de 40 anos do Andes-SN, desde quando ainda era associação docente. Assim, as primeiras associações docentes das instituições de ensino públicas no Brasil foram organizadas para defender a estruturação do sistema público de ensino superior, se posicionando, já na década de 1980, contra os princípios da 


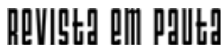

\} EDUCAÇÃO SUPERIOR PÚBLICA E O FUTURE-SE - GONÇALVES FH, A.; FARAGE, E. \}

DOI: $10.12957 /$ REP.2019.45210

privatização, contra o modelo de estrutura universitária centralizada ${ }^{5}$ construído em vários países da América Latina e contra a parceria e subordinação da produção do conhecimento aos interesses do capital em expansão no Brasil.

Atualmente, uma parte dos países da América Latina já possui algum tipo de cobrança nas universidades públicas, seja de mensalidade, de semestralidade e/ou de anuidade; uma parte das instituições não é estruturada a partir de corpo docente e técnico-administrativo com carreira no funcionalismo público. Além disso, não possui dedicação exclusiva (DE), defendida pelo Andes-SN como condição para a estruturação da universidade pública a partir do tripé ensino-pesquisa-extensão. Nesse sentido, a luta sindical, autônoma, independente de governos, partidos e administrações, deve ser considerada, junto com a resistência e luta dos movimentos sociais, a responsável pela manutenção da atual estrutura pública existente.

No que tange à forma, o programa Future-se, diferentemente de muitas outras iniciativas de contrarreformas universitárias, reserva alguma semelhança com os acordos MEC-Usaid realizados no período da Ditadura empresarial-civil-militar na década de 1960, quando os militares, através do Ministério da Educação, firmaram acordos com os Estados Unidos para implementar o modelo norte-americano de educação no Brasil, desde o nível básico até o nível superior. Mais tarde, foi possível identificar que os acordos, entre as muitas mudanças planejadas, tinham como foco a privatização da educação pública, assim como a sua fragmentação. Além de reduzir o tempo do ensino obrigatório, eliminou, à época, matérias importantes do currículo, como Educação Política e Filosofia, e instituiu a disciplina de Educação Moral e Cívica. Essa reforma universitária foi imposta, não havendo nenhum tipo de negociação ou diálogo com a comunidade acadêmica, organizações de classe e científicas. Ou seja, a mesma forma imposta através do Future-se. Em sua forma, absolutamente autoritária, revela-se o seu conteúdo absolutamente privatista.

Por outro lado, é fundamental reconhecer que, mesmo com a estruturação precária, a expansão universitária dos últimos dez anos foi responsável pela ampliação do acesso de jovens pobres à universidade pública, assim como de negros e negras, povos indígenas, favelados, LGBTQ+ e quiIombolas. Ou seja, a universidade pública brasileira tornou-se, sem nenhuma dúvida, mais popular, mais democrática e mais diversificada, contribuindo para dar visibilidade aos que o capitalismo quer tornar invisíveis.

A expansão das universidades federais aconteceu de forma significativa, segundo dados do Inep (2017), passando de 45 instituições com 148 campi, em 2002, para cerca de 327 campi de 65 universidades até

\footnotetext{
${ }^{5} \mathrm{Em}$ uma parte dos países da América Latina, a estrutura da rede universitária pública segue o modelo centralizado, das universidades nacionais, com pouca expansão de campi e de universidades menores pelos estados/províncias/ municípios. Na Argentina, Colômbia, Chile, México, Uruguai, Equador, entre outros, temos as universidades nacionais, sediadas na capital do país, seguindo um modelo distinto do brasileiro.
} 


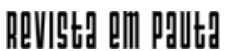

\} EDUCAÇÃO SUPERIOR PÚBLICA E O FUTURE-SE - GONÇALVES FH, A.; FARAGE, E. \}

DOI: $10.12957 /$ REP.2019.45210

2015. Vale ressaltar que algumas das chamadas "novas universidades" foram fruto do desmembramento de antigos campi de universidades federais, mas ainda assim representam uma expansão.

O Future-se pretende-se grande, colocando-se desde sua apresentação como uma profunda reformulação do ensino superior público e questionando tudo o que até agora foi construído, com impacto, inclusive, no ensino básico. É ousado, já que pretende, com sua aprovação, alterar e/ ou regulamentar 17 leis .

O que há de comum nas mudanças propostas para as diversas leis? A intenção de aprofundar o caráter privado da educação, que já estava estabelecido no projeto de reforma do Estado do governo de Fernando Henrique Cardoso (1995-2003), gerenciado por Bresser Pereira, então ministro da Administração Federal e Reforma do Estado (Mare), entre 1995-1998. A fatura desse projeto, mais uma vez, será paga pelos trabalhadores, já que o que está em jogo é uma verdadeira desestruturação do sentido e estrutura pública das universidades e institutos.

Trata-se de mais uma privatização, no formato não clássico, assim como foi a Empresa Brasileira de Serviços Hospitalares (EBSERH) e a Funpresp, já que não se pretende leiloar as instituições de ensino, mas sim vender ou subordinar ao mercado algumas de suas partes, colocando a capacidade de produzir das instituições públicas de ensino e o "selo" da gestão federal para produzir para a iniciativa privada. Um explícito exemplo é o artigo 42, parágrafo $4^{\circ}$, do projeto de lei do Future-se, que permite o atendimento aos planos de saúde nos hospitais universitários gerenciados pela EBSERH, afirmando "os hospitais universitários poderão aceitar convênios de planos privados de assistência à saúde" (BRASIL, 2019). Nessa estratégia de manter a aparência pública e a essência privada e/ou subordinada à iniciativa privada de quem será a prioridade no atendimento, do paciente do SUS ou do paciente do plano de saúde?

As mudanças são muitas e se revelam como um verdadeiro assalto ao fundo público em favor do capital, com um implícito objetivo de retomar

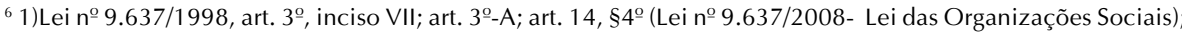
2) Lei $n^{\circ}$ 10.973/2004 (Lei $n^{\circ}$ 10.973/2004 - Lei de Incentivos à inovação e à pesquisa científica e tecnológica); 3) Lei $\mathrm{n}^{\circ} 13.243 / 2016$, art. $1^{\circ}$, incisos I a XIV e $\S 2^{\circ}$; art. $3^{\circ}$-C ; art. $4^{\circ} \$ \S 1^{\circ}$ e e $2^{\circ}$; art. 10 ; art. 26-B (Lei $n^{\circ}$ 13.243/ 2016- Lei de estímulos ao desenvolvimento científico e à pesquisa); 4) Lei $n^{\circ}$ 9.394/1996 art. 48, $\$ 2^{\circ}$ e $\$ 4^{\circ}$; art. 66, §§ $1^{\circ}$ e $2^{\circ}$ (Lei no 9.394/1996 - Lei de Diretrizes e Bases da Educação); 5) Lei no 8.313/1991, art. 18, §3º, alínea i e $\$ 4^{\circ}$ (Lei $n^{\circ}$ 8.313/1991 - Lei do PRONAC); 6) Lei no 10.735/2003, art. 1을 inciso I, alínea d (Lei $n^{\circ}$ 10.735/2003 - Lei dos Projetos de Interesse Social - PIPS); 7) Lei $n^{\circ} 12.772 / 2012$, art. 21, inciso XIII (Lei $n^{\circ}$ 12.772/2012 - Lei da Carreira do Magistério Superior); 8) Lei no 7.827/1989, art. 4으, inciso III (Lei no 7.827/1989 - Lei dos Fundos Constitucionais do Norte, Nordeste e Centro-Oeste); 9) Lei no 8.010/1990, art. 1을 $\$ 3^{\circ}$ (Lei no 8.010/1990 - Lei de imposto de importação sobre bens destinados à pesquisa); 10) Lei $\mathrm{n}^{\circ}$ 8.032/1990, art. $2^{\circ}$, inciso l, alínea g (Lei no 8.032/1990 - Lei de isenção ou redução de imposto de importação); 11) - Lei no 9.249/ 1995, art. 13, §2, inciso II e inciso III, alíneas a, b (Lei no 9.249/1995 - Lei de Imposto de Renda de Pessoas Jurídicas); 12) Lei no 9.250/1995, art. 12, inciso IX, $\$ 1^{\circ}$ (Lei no 9.250/1995 - Lei do Imposto de Renda de Pessoas Físicas); 13) Lei no 9.532/1997, art. 22 (Lei no 9.532/1997 - Lei da legislação tributária federal);14) Lei no 8.248/ 1991, art. 4은 (Lei no 8.248/1991 - Lei sobre capacitação e competitividade do setor de informática); 15) - Lei nº 9.991/2000, art. 4ㅇ-A, §6으, incisos IV e V (Lei no 9.991/2000 - Lei de Pesquisa e Desenvolvimento no setor de energia elétrica); 16) Lei no 11.196/2005, art. 19-A (Lei de tributação especial em serviços de tecnologia); e 17) Lei $n^{\circ} 12.550 / 2011$, art. $3^{\circ}$, $\$ 1^{\circ}$ e $\S 4^{\circ}$ (Lei ${ }^{\circ}$ 12.550/2011 - Lei da EBSERH).
} 


\section{ReVIStg a d P p putt}

\} EDUCAÇÃO SUPERIOR PÚBLICA E O FUTURE-SE - GONÇALVES FH, A.; FARAGE, E. \}

DOI: $10.12957 /$ REP.2019.45210

os princípios da colonização, a partir da subordinação da educação e da produção do conhecimento aos interesses do capital. Nesse sentido, o projeto deve ser analisado a partir de quatro grandes eixos: a) gestão institucional; b) gestão de pessoal; c) formação; e d) acesso e permanência de estudantes. Sobre cada um desses pontos, merece destaque:

a) Gestão institucional - A base do projeto é uma profunda reestruturação da universidade pública brasileira, que passa por uma nova forma de gestão institucional via OS e fundos públicos de gerenciamento de bens e serviços das instituições de ensino. Essa é uma transformação estrutural que altera, de forma significativa, o estatuto social da universidade e dos institutos federais, com o objetivo central de usurpar o fundo público. Outro elemento estruturante é o fato de essa mudança gerencial impor uma fórmula empresarial para as instituições de educação, que prevê desde a venda do espaço físico para propagandas de empresas, como especificado no artigo 15을 visando à "compensação financeira" (naming rights), até a contratação de OS sem chamada pública, como especificado no parágrafo 1 o do artigo $3^{\circ}$.

Vale destacar que os fundos de investimento, tratados no artigo 9으, são uma forma de burlar, por parte de empresas, o pagamento de impostos, uma vez que, segundo o artigo $41^{\circ}$, a lei de tributação sofrerá mudanças, possibilitando a isenção fiscal para empresas que "investirem" no fundo. Além disso, como explicitado no parágrafo 4 do artigo 9o, sobre "Os rendimentos do fundo de investimento destinados ao FUTURE-SE, não incidirão qualquer imposto ou contribuição social de competência da União" (BRASIL, 2019). O fundo de investimento, que também será alimentado por recursos públicos, é uma explicita usurpação do fundo público pela iniciativa privada.

Essa nova modalidade de gestão põe fim à autonomia universitária prevista no artigo 207 da CF/88 e redefine o papel dos gestores das instituições de ensino que, possivelmente articulada ao decreto 9.725/2019 de extinção de cargos comissionados, pode significar a redução do staff das universidades e institutos federais, além de esvaziar politicamente a função de reitores e pró-reitores.

b) Gestão de pessoal - A gestão de pessoal é outro ponto estruturante do projeto, que, articulado ao anúncio de suspensão de concursos públicos e às mudanças impostas pelo decreto n. 9.739/2019, que prevê que todo concurso público deve passar pela autorização do ministro da Economia, anunciam o fim das contratações com base no Regime Jurídico Único da União (RJU). Essa nova forma de gestão de pessoal anunciada no Future-se despreza os técnicos administrativos, levando-nos a concluir que sua forma de contratação será por OS.

Para os docentes, impulsiona a proposta do professor(a) "empreendedor(a)", além de deixar aberta a possibilidade de inserção por OS. 


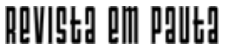

\} EDUCAÇÃO SUPERIOR PÚBLICA E O FUTURE-SE - GONÇALVES FH, A.; FARAGE, E. \}

DOI: $10.12957 /$ REP.2019.45210

Outro elemento de enorme preocupação, já introduzido anteriormente pela lei n. 13.415/2017 da contrarreforma do ensino médio, é o "notório saber", previsto no artigo 29 do Future-se como mudança a ser realiza na LDB, assim como a facilitação de revalidação de diplomas adquiridos em instituições estrangeiras de "alto desempenho".

Ainda na perspectiva do(a) professor(a) empreendedor(a), que poderá, segundo o artigo 14, inciso I, se envolver na criação e desenvolvimento de "parques e polos tecnológicos, incubadoras e start-ups" ou criar uma "Sociedade de Propósito Específico-SPE", como previsto no artigo 16, a competição entre os docentes e alunos será o fio condutor da produção do conhecimento para fins de mercado (BRASIL, 2019). E para o(a)s "empreendedore(a)s", será concedida a opção de, colocando fim ao tripé ensinopesquisa-extensão, realizar sua carga horária de trabalho apenas em sala de aula, como previsto no artigo $18^{\circ}$ do Future-se.

c) Formação - Para a formação, a prerrogativa do Future-se é de atendimento exclusivo às exigências do mercado. A produção do conhecimento será subalternizada e dependente das parcerias público-privadas. Dessa maneira, os estudantes serão atingidos de forma direta, em vários aspectos, com destaque: a) para a diminuição do investimento estatal na assistência estudantil; b) para a intensificação das diferenças de condições para ensino-aprendizagem ofertadas entre os cursos; c) para a subordinação da produção do conhecimento aos interesses do mercado: se o interesse de pesquisa do estudante não conseguir "investidor", sua pesquisa não será realizada; d) para o empobrecimento do sentido pleno da universidade, que não será mais pautada pelo tripé-ensino-pesquisa-extensão; e e) para o fato de que a universidade estará mais empobrecida com a imposição da padronização das atividades extraclasse, já que a diversidade não é algo que interesse ao mercado, e com isso contribuirá menos para o pensamento crítico e amplo, para o acesso às diferentes teorias, se fechando para a pluralidade e para o contraditório.

Essa perspectiva de formação atravessa todo o projeto do Futurese, com destaque para os artigos que colocam os alunos como empreendedores, fundadores de "start-ups". A facilitação na incorporação de disciplinas realizadas a distância, em plataformas tecnológicas (artigo 20, inciso III), e o artigo 44, que institui "o Dia do Estudante Empreendedor", também revelam a perspectiva aligeirada que se pretende dar à formação.

Outro elemento que merece nossa atenção, e que terá impacto avassalador na formação dos estudantes, são as avaliações às quais as instituições de ensino vão ser submetidas. Tudo indica que, seguindo as orientações dos organismos internacionais, como vários países da América Latina estão realizando, será imposta uma avaliação padronizada, que implica a reestruturação dos conteúdos para que as instituições de ensino fiquem bem nas pontuações e nos ranqueamentos, que podem vir a gerar recursos e prêmios. Se a avaliação é padronizada, também o conteúdo passa 


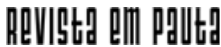

\} EDUCAÇÃO SUPERIOR PÚBLICA E O FUTURE-SE - GONÇALVES FH, A.; FARAGE, E. \}

DOI: $10.12957 /$ REP.2019.45210

a ser padronizado, empobrecendo e homogeneizando a formação profissional.

d) Acesso e permanência de estudantes - Nesse quesito, o projeto Future-se, ao desconsiderar a realidade social e os grupos historicamente marginalizados, como indígenas, quilombolas, comunidade trans, favelado(a)s, ribeirinhos, negros e negras, pessoas com deficiência e mulheres, busca impor novamente a INVISIBILIDADE desses segmentos, visando retornar à elitização do ensino superior no Brasil. Será uma universidade que novamente buscará a invisibilidade e tentará, mais uma vez, contar a história dos colonizadores, do(a)s branco(a)s, dos homens e heterossexuais.

Além disso, como previsto no artigo 14, inciso VII, as OS devem "promover ações de empregabilidade para os alunos das instituições", ou seja, a(o)s estudantes que não conseguirem um lugar de "empreendedor" possivelmente será imposto algum tipo de trabalho, dentro da própria Ifes e/ou OS, em substituição de servidores técnico-administrativos e trabaIhadore(a)s terceirizado(a)s. De fato o(a)s estudantes têm tudo a perder, em especial, o conhecimento e a liberdade de pensar.

Por todos esses motivos, compreendemos que o projeto aponta para a desresponsabilização do Estado e a privatização da universidade e institutos federais, buscando regulamentar várias mudanças realizadas por governos anteriores, que, por conta da resistência dos movimentos organizados, não foram implementadas $100 \%$ em seu cunho privatista. Na luta pela CF/88, resistimos e, apesar de algumas significativas perdas, conseguimos barrar, naquele momento, o financiamento privado como fonte de recursos para a educação superior. $\mathrm{Na} L \mathrm{LB}$, conseguimos resistir à imposição do ensino a distância, em maior proporção, no ensino presencial, limitandoo a 20\% da carga horária; no novo Marco de Ciência, Tecnologia e Inovação de 2016, que não regulamentou a forma de cessão dos espaços públicos e servidores públicos à iniciativa privada; na EBSERH, resistimos ao atendimento de planos de saúde nos hospitais universitários.

Ou seja, o que se pretende é levar às últimas consequências o projeto de contrarreforma da educação em favor do capital, à efetiva transformação da educação superior em mercadoria também no espaço público.

\section{Considerações finais}

O Future-se, entre as tantas destruições já mencionadas, ainda incidirá sobre a ampliação do adoecimento docente, na medida em que transformará o ambiente de trabalho em um espaço cada vez mais competitivo. Além disso, esse projeto desvaloriza a produção do conhecimento no nível da pós-graduação; privilegia algumas áreas de conhecimento, em especial as de interesse do mercado; destitui a educação de seu sentido central, transformando-a, de forma definitiva, em mercadoria; e transforma a uni- 


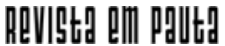

\} EDUCAÇÃO SUPERIOR PÚBLICA E O FUTURE-SE - GONÇALVES FH, A.; FARAGE, E. \}

DOI: $10.12957 /$ REP.2019.45210

versidade e os institutos federais em meros "selos" da iniciativa privada para a produção do conhecimento, deixando em último plano a produção do conhecimento como perspectiva para o desenvolvimento social do país.

A universidade, para a parte dos docentes e técnico-administrativos que se encantarem com o projeto e forem atrás da promessa de enriquecimento, realizada pelo Ministro da Educação Abraham Weintraub, será apenas um "bico", e não mais o espaço da dedicação exclusiva. Assim daremos mais um passo na destruição da carreira docente e da educação superior pública, como previsto nas orientações dos organismos internacionais, em especial no projeto "Um ajuste Justo", do Banco Mundial de 2017, em cumprimento ao proposto no Consenso de Washington e no Processo de Bolonha de 1999.

O Future-se é a FATURA da universidade e dos institutos federais públicos, é o VENDE-SE da educação superior, um salto ao passado de recolonização. Resistir e lutar contra ele é nossa obrigação, por nós e pelas gerações que virão. No presente e no futuro, na certeza de que só com organização coletiva seremos capazes de barrar os retrocessos, é necessário que exijamos a imediata recomposição orçamentária do ensino superior público, e que façamos a defesa de uma educação estatal, laica, antipatriarcal, socialmente referenciada e democrática! 


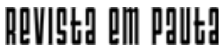

\} EDUCAÇÃO SUPERIOR PÚBLICA E O FUTURE-SE - GONÇALVES FH, A.; FARAGE, E. ]

DOI: $10.12957 /$ REP.2019.45210

\section{Referências}

ADUFF. Caderno de expansão e condições de trabalho docente. Niterói: GTPE/Aduff-SSIND, 2013.

ANDERSON, P. Balanço do neoliberalismo. In: ANDERSON, P. Pós-Neoliberalismo - As políticas sociais e o Estado democrático. Rio de Janeiro: Editora Paz e Terra, 1995.

ANDES. Proposta do Andes-SN para a universidade brasileira. Cadernos Andes, Brasília, n. 2, jan. 2013.

BRASIL. Constituição Federal. Diário Oficial, Brasília, 1988.

BRASIL. Ministério da Administração Federal e da Reforma do Estado. Câmara de Reforma do Estado. Plano Diretor da Reforma do Aparelho do Estado. Diário Oficial, Brasília, 1995.

BRASIL. Projeto de Lei Future-se. Diário Oficial, Brasília, 2019.

FERNANDES, F. Capitalismo dependente e classes sociais na América Latina. Rio de Janeiro. Editora Zahar, 1975.

IAMAMOTO, M. V.; CARVALHO, R. de. Relações sociais e Serviço Social no Brasil - Esboço de uma interpretação histórico metodológica. São Paulo: Editora Cortez, 1995.

LIMA, K. R. de S. Capitalismo dependente e "Reforma Universitária Consentida": a contribuição de Florestan Fernandes para a superação dos dilemas educacionais brasileiros. In: REUNIÃO ANUAL DA ANPED, 28., Caxambu, 2005. Anais... Caxambu, 2005.

LIMA, K. R. de S. Contra-Reforma na educação superior: de FHC a Lula. São Paulo: Editora Xamã, 2007.

MARX, K. A chamada acumulação primitiva. In: MARX, K. O capital -Crítica da Economia Política. Livro 1, vol. 2. Rio de Janeiro: Editora Civilização Brasileira, 2001.

MARX, K. Contribuição à economia política. São Paulo. Editora Expressão Popular, 2007.

MARX, K. Para a questão judaica. São Paulo: Editora Expressão Popular, 2009. MÉSZÁROS, I. A educação para além do capital. São Paulo: Editora Boitempo, 2005.

SGUISSARDI, V. Modelo de expansão da educação superior no Brasil: predomínio privado/mercantil e desafios para a regulação e a formação universitária. Educação e Sociedade, Campinas, v. 29, n. 105, set./dez. 2008.

DOI: $10.12957 /$ rep.2019.45210 


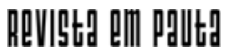

\} EDUCAÇÃO SUPERIOR PÚBLICA E O FUTURE-SE - GONÇALVES FH, A.; FARAGE, E. \}

DOI: $10.12957 /$ REP.2019.45210

Recebido em 20 de agosto de 2019.

Aprovado para publicação em 02 de setembro de 2019

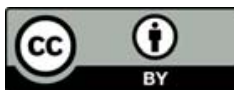

A Revista Em Pauta: Teoria Social e Realidade Contemporânea está licenciada com uma Licença Creative Commons Atribuição 4.0 Internacional. 